\title{
探析建筑主体结构工程质量检测
}

\author{
黄婧 \\ 信阳市瑞丰建设工程检测有限公司
}

DOI:10.32629/btr.v3i5.3143

[摘 要] 为了确保建筑工程施工质量安全,应对建筑主体结构进行质量检测。只有充分落实好质量检测工作,才能够保证建筑工程质量,给人们 工作和居住提供安全环境, 促进我国建筑行业更好发展。在建筑工程主体结构质量检测过程中,一般采用样本检测方式, 也就是由检测工作人员 根据样本进行质量检测。在实际操作过程中,任何违规操作都会给检测结果带来影响,所以需要检测人员严格按照操作要求进行,保证检测结果 的真实性,给建筑工程施工建设提供数据参考。

[关键词] 建筑工程; 主体结构; 质量检测

\section{1 我国建筑工程主体结构质量检测工作基本特点}

结合现阶段我国建筑工程主体结构质量检测工作实际情况来看, 其基 本特点主要包括: 首先, 合法性。建筑工程质量检测工作是由国家方面要 求和发起的、相关职能部门负责落实的一项工作, 在检测工作中需全面遵 循《建设工程质量检测管理办法》中的各项要求, 体现了该项工作的合法 性特点。其次, 公正性。建筑工程主体结构质量检测工作主体受到相关利 益者的委托, 根据相关法律规定通过细致的质检工作而出具检测报告, 各 项工作环节严格而标准, 体现了该项工作的公正性与公平性。再次, 真实 性。检测部门最终所出具的检测报告体现的是真实的检测结果, 因此具有 真实性和有效性特点。第四, 准确性。检测部门的检测工作以相关法律及 规章制度为原则, 对检测中的相关资料及凭证进行保留, 具有较高的准确 性。第五, 独特性。由于建筑工程规模以及结构等具有一定的差异, 每个建 筑工程的质量评估仅代表该工程的实际质量情况, 这就赋予该项工作相应 的独特性特点。

\section{2 建筑工程主体结构质量检测的有效对策}

2. 1 制定质量检测方案

首先, 合理选择检测样本。在建筑工程主体结构质量检测过程中, 应该 结合实际情况合理选择样板, 在样板选择中, 应该按照国家有关标准进行, 其基本原则在于结构检测应选择相同类型的构件。一般情况下, 普通抽样 可以结合结构和材料类型进行选择。第一级根据结构类型, 可以划分成钢 筋混凝土结构、钢结构及砌体结构; 第二级结合构件类型, 可以划分成墙、 梁、柱等; 第三级可以根据材料种类进行划分, 也可以根据测量具体情况 进行区分。如果存在有争议的构件, 在抽样检测过程中, 需要结合现场实际 情况选择对应检测方式和类型, 分别对有疑义的构件进行检查, 便于明确 问题构件是否满足建筑工程施工标准。其次, 制定建筑工程主体结构质量 检测方案。在制定检测方案过程中, 应该对被检测建筑结构整体情况有所 了解, 结合检测目标确定检测样本空间, 之后对建筑主体整体情况进行检 测。例如, 建筑位移、建筑变形、建筑结构裂缝等。与此同时, 比较建筑施 工图纸、施工结构、材料构件等, 及时找出施工建设中可能存在的问题, 明确构件和建筑材料强度是否满足工程建设要求。此外, 需要对当地地质 环境、水文情况进行判断, 给建筑工程主体结构现场检测方案制定提供数 据参考。在现场质量检测过程中, 包含的内容有建筑工程外观质量、建筑 工程尺寸、材料质量及主体构件等。

2. 2 做好建筑材料检测工作
从目前情况来看, 大多数建筑工程主体结构采用的结构主要以钢筋混 凝土结构为主, 所以在材料检测过程中, 包含的内容有钢筋、水泥、骨料及 钢材焊接检测。在钢材检测过程中, 一般采取抽样检测方式, 重点对钢筋力 学性能进行检查。在具体检测中, 应该保证每一批次钢筋型号、类型统一。 对于水泥及骨料等材料检测, 一般是对其质量、化学性能等进行检测, 并且 应该重点核查混凝土配比情况及混凝土强度。如果建筑工程主体采用的商 品混凝土, 则应该重点检查拌合物塌落情况; 对于主体结构钢筋焊接位置, 一般采用超声波检测方式, 如果在检测中发现钢筋断裂、焊接不严等问题, 应该对钢筋化学成分重点检查。如果在工程中, 则应该对钢筋焊接和设备 连接质量进行检查。

2.3加强建筑主体结构检测

在对建筑工程混凝土结构检测过程中, 通常采取两种方式, 一个是回 弹检测方式, 该方式则是通过对混凝土结构表面敲击, 根据重锤反弹高度 情况进行测量。在应用回弹检测方式中, 对重锤动量有着严格要求, 并且需 要根据建筑工程结构类型明确检测位置, 根据回弹检测方式应用要求进行 测量, 保证质量测量结果的真实性。另一个是钻芯检测方法。该方式也被 称之为破损检测, 通常是对回弹检测数据有所疑惑的情况下才会采用钻芯 检测方法。在应用该方法过程中, 需要保证钻芯位置设定精准, 避开主要受 力钢筋位置。该检测方式对测量混凝土构件抗压强度值有着精准的效果, 一般在对混凝土构件强度存在疑惑的情况下才会使用此方式。

\section{3 结束语}

建筑工程中主体结构质量在实施检测的过程中步骤相对较为复杂, 其 检测难度较大, 在这种情况下进行检测就会出现一些失误, 这也降低了检 测结果的准确程度。建筑工程在实施主体结构质量检测管理的时候, 一些 建筑工程企业没有对相应的监督管理部门进行设立, 这无法提升主体结构 质量检测的有效程度。所以企业需要对质量检测工作给予一定的重视, 并 借助一些管理手段为工程的质量建设做出保证。

[参考文献]

[1]董海燕. 某工程主体结构施工质量检测鉴定 [J]. 四川水 泥,2019,(10):240.

[2]安建科,杜栍煊.论建筑工程主体结构检测在工程实体质量监督中 的作用 [J].建材与装饰,2016,(26):79-80.

[3]张玉稳,胡玉秋. 某工程主体结构施工质量检测鉴定[J].四川建 材,2018,44(06):28-29. 